\begin{tabular}{|c|c|c|c|c|c|c|c|}
\hline $\begin{array}{l}\text { Module } 6 \\
\text { Economy and } \\
\text { Development }\end{array}$ & $\begin{array}{l}\text { Reading and } \\
\text { comprehending } \\
\text { texts about } \\
\text { the economy. } \\
\text { Comprehension } \\
\text { and language } \\
\text { in context } \\
\text { questions. }\end{array}$ & الأسماء المضمسة، المبني & $\begin{array}{l}\text { Learning new } \\
\text { vocabulary on } \\
\text { the economy. }\end{array}$ & $\begin{array}{l}\text { Listening to } \\
\text { a text } \\
\text { on Arab } \\
\text { revolutions and } \\
\text { their knock-on } \\
\text { effect on the } \\
\text { economy. } \\
\text { Comprehension } \\
\text { questions. }\end{array}$ & $\begin{array}{l}\text { Translating } \\
\text { paragraphs, } \\
\text { texts and } \\
\text { expressions } \\
\text { about the } \\
\text { economy into } \\
\text { English. }\end{array}$ & $\begin{array}{l}\text { Using } \\
\text { expressions } \\
\text { pertaining to } \\
\text { expenditure in } \\
\text { context; using } \\
\text { expressions of } \\
\text { causality and } \\
\text { effect to write } \\
\text { an essay about } \\
\text { unemployment. }\end{array}$ & $\begin{array}{l}\text { Using } \\
\text { expressions } \\
\text { to discuss } \\
\text { topics } \\
\text { related } \\
\text { to the } \\
\text { economy. }\end{array}$ \\
\hline $\begin{array}{l}\text { Module } 7 \\
\text { Sports }\end{array}$ & $\begin{array}{l}\text { Reading texts } \\
\text { about sports. } \\
\text { Answering } \\
\text { comprehension } \\
\text { questions. }\end{array}$ & الماضي المجني & $\begin{array}{l}\text { Learning } \\
\text { and using } \\
\text { vocabulary } \\
\text { about sports. }\end{array}$ & $\begin{array}{l}\text { Listening to } \\
\text { texts } \\
\text { about sports } \\
\text { and tourism. A } \\
\text { glossary and } \\
\text { drills. }\end{array}$ & $\begin{array}{l}\text { Translating } \\
\text { texts about } \\
\text { sports from and } \\
\text { into Arabic. }\end{array}$ & $\begin{array}{l}\text { Using } \\
\text { expressions of } \\
\text { preference to } \\
\text { write about } \\
\text { sports. Using } \\
\text { expressions } \\
\text { related to } \\
\text { success and } \\
\text { failure. }\end{array}$ & $\begin{array}{l}\text { Discussing } \\
\text { different } \\
\text { aspects } \\
\text { of sports, } \\
\text { including } \\
\text { the impact } \\
\text { of sports on } \\
\text { health and } \\
\text { the pros of } \\
\text { sports. }\end{array}$ \\
\hline $\begin{array}{l}\text { Module } 8 \\
\text { Arts and } \\
\text { Literature }\end{array}$ & $\begin{array}{l}\text { Reading texts } \\
\text { about Arabic } \\
\text { literature. } \\
\text { Answering } \\
\text { comprehension } \\
\text { questions. }\end{array}$ & 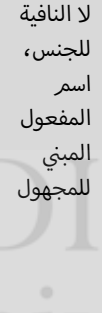 & $\begin{array}{l}\text { Learning and } \\
\text { using words, } \\
\text { phrases } \\
\text { and literary } \\
\text { expressions. }\end{array}$ & $\begin{array}{l}\text { Listening to } \\
\text { texts } \\
\text { about Arabic } \\
\text { literature. A } \\
\text { glossary and } \\
\text { drills. }\end{array}$ & $\begin{array}{l}\text { Translation of } \\
\text { literary texts } \\
\text { into English. }\end{array}$ & $\begin{array}{l}\text { Using } \\
\text { expressions } \\
\text { of preference } \\
\text { to write } \\
\text { about Arabic } \\
\text { literature. } \\
\text { Learning about } \\
\text { literature and } \\
\text { prominent Arab }\end{array}$ & $\begin{array}{l}\text { Discussing } \\
\text { Arabic } \\
\text { literature } \\
\text { and writers, } \\
\text { and other } \\
\text { related } \\
\text { topics. }\end{array}$ \\
\hline
\end{tabular}

\title{
Key to Symbols
}

\section{A/Z Glossary \\ ? Comprehension questions}

(o) Language in context

Translation
Listening

Answer key

6699 Speaking

G Grammar

at Writing 